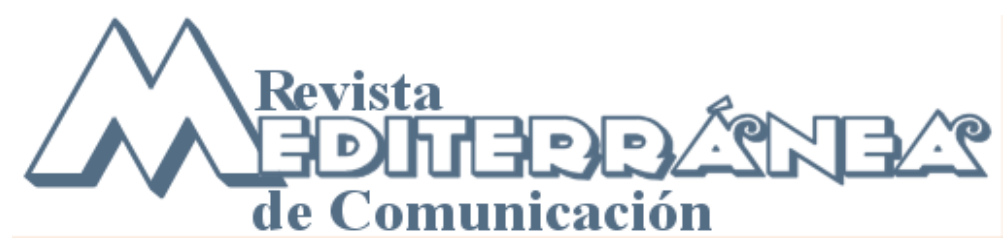

\title{
La imagen científica: tecnología y artefacto
}

\section{Scientific Images: Technology and artifac}

\author{
Dr. Francisco López-Cantos \\ Profesor de la Universidad Jaime I de Castellón ${ }^{1}$. España. \\ flopez@com.uji.es
}

\begin{abstract}
Resumen
El artículo revisa las características y evolución de los distintos sistemas de reproducción de imágenes científicas y el impacto que históricamente han tenido en el desarrollo de la investigación y el conocimiento. Para ello realiza un acercamiento crítico a las tecnologías que subyacen en los sistemas e instrumentación científica destinados a la elaboración de imágenes con el fin de explicitar sus mecanismos y limitaciones contingentes para la elaboración de imágenes concluyendo, de este modo, que dichas imágenes sólo se pueden definir, históricamente y en la actualidad, en tanto que artefactos discursivos irremediablemente ligados a las instrumentos con que se han generado.
\end{abstract}

\section{Palabras clave}

Imagen, investigación, epistemología, España.

\section{Abstract}

This article revises the characteristics and evolution of the different systems of reproduction of scientific images and the historical impact it has had in the development of the investigation and the Knowledge. For it has carried out a critical study into the technologies that underlie the systems and scientific instrumentation which is dedicated to the elaboration of images with the objective to make clear their mechanisms and contingent limitations for representing Nature with images. The text concludes that scientific images can only be defined, historically and at the present time, as discursive artifacts in hopeless relation to linked devices, to the instruments with which they have been generated

\section{Keywords}

Image, research, epistemology, Spain.

Sumario: 1. Introducción. 2. Ilustración y Fotografía: El tránsito a la objetividad mecánica en Ciencia. 3. Instrumentación electrónica: Más lejos, más cerca, más color. 4. Los límites

Forma de citar este artículo: Baamonde Silva, X. M. (2010): "Ferias + web 2.0: medio definitivo de comunicación profesional", en Revista Mediterránea de comunicación, 1, pp. 98-112. Recuperado el día de mes de año (añadir enlace) 
de la exploración: Imágenes científicas y Artefactos tecnológicos. 5. Conclusiones. 6. Bibliografía. 7. Notas.

Summary: 1. Introduction. 2. Illustration and Photography: The transition to mechanical objectivity in science. 3. Electronic instruments: Further, closer, more color. 4. The limits of exploration: Images scientific and technological artifacts. 5. Conclusions. 6. Bibliography. 7. Notes.

\section{Introducción}

"La fotografía común y, sobre todo, la fotografía en color, constituyen distracción incomparable para el
trabajador intelectual. En los prosaísmos y miserias de la lucha profesional o de la vida oficinesca, pone
un poco de poesía y algo de emoción imprevista. Sus placeres, eminentemente higiénicos y educadores,
carecen de la tediosa monotonía del billar o de la ruda y peligrosa fatiga de la caza. Faltaba todavía
alcanzar el soñado ideal, es decir, descubrir medios prácticos para fotografiar los colores, trocando la
siniestra visión de búho por la riente visión de hombre. Y este ideal, quimera inaccesible al parecer, se ha
realizado al fin. Hétenos ya, gracias al maravilloso invento de Lumiere, emancipados de la intolerable
esclavitud del blanco y negro. El devoto de la heliocromía no debe ser rutinario practicón atenido a
recetas y formularios, al modo del carpintero que, aguijado por la necesidad, abandona la garlopa por el
objetivo. Ocioso parece insistir en el vulgar argumento de que sólo acierta quien sabe. La interpretación
de los resultados obtenidos y el remedio de los fracasos y accidentes, deben buscarse en la clara
comprensión del mecanismo físico-químico de cada operación fotográfica". Santiago Ramón y Cajal, $1912^{2}$

El ideal de que habla Ramón y Cajal para colmar la percepción con la consecución de reproducciones en color más allá de los límites de unos sistemas de obtención de imágenes entonces monocromáticos provocó los desvelos de no pocos científicos a lo largo del siglo pasado.

El sistema de obtención de colores por métodos aditivos había sido demostrado experimentalmente hacia la década de 1850, siguiendo la estela de las teorías tricromáticas expuestas por Young en 1802 y reelaboradas por Hemholtz en 1852, por el físico James Clerk Maxwell quien, además, elaboró una teoría unificada de los fenómenos eléctricos y magnéticos en la que abordaba el estudio de la luz como uno más de ellos. Dando a la luz carácter de onda electromagnética se superaban los condicionantes de la física newtoniana en relación a los problemas de las acciones a distancia, ahora explicados a partir de los fenómenos electromagnéticos y también, entre otros, se podían explicar los hallazgos resultantes de los experimentos del músico y astrónomo Frederick William Herschel, quien con la ayuda de un termómetro encontró, en el año 1800, que había emanaciones de energía por debajo del rojo que no eran visibles, energía a la que denominó luz infrarroja.

De igual manera, con la teoría electromagnética se podía entender el descubrimiento que realizó el físico alemán Johann Ritter, sólo un año después de Herschel, al comprobar experimentalmente que exponiendo cloruro de plata al violeta extremo y eliminando en el laboratorio las radiaciones visibles el compuesto seguía reaccionando sin presencia explícita de luz visible, e incluso lo hacía con mayor rapidez, lo cual le llevó a determinar que había un tipo de radiación no visible que ejercía su influencia sobre el compuesto, a la que denominaría luz ultravioleta por ubicarse espacialmente más allá de esa parte del espectro visible cuando se hacían pruebas al respecto. Todo ello, en conjunción con el desarrollo de mecanismos de control sobre la reacción que se 
producía en ciertos materiales al ser expuestos a la luz, fenómeno del que se tiene noticia desde la Grecia clásica y que empezó a ser conocido empíricamente a partir de los primeros experimentos del profesor universitario alemán J. Schulze para analizar los efectos que la luz producía en un compuesto que contenía ácido nítrico, plata y yeso contenido en una botella sobre la que colocaba recortes de papel perforado para así conseguir registrar dichos motivos, dio lugar a un sistema de registro de imágenes hasta entonces inexistente: la fotografía.

Sus inventores, Niépcè y Daguerre, se habían expresado en idéntico sentido respecto a las características del nuevo procedimiento de registro de imágenes que venían desarrollando, y ninguno de los dos pretendía otra cosa que realizar copias "verdaderas" de la Naturaleza, con afán de progresiva perfección de la técnica hasta alcanzar cotas de calidad inmejorables. Con idénticas premisas trabajaba Henry Fox Talbot, experto reconocido mundialmente como botánico y matemático y que poseía también amplios conocimientos de óptica y química, además de ser poeta y político, cuando comenzó, hacia 1839, a desarrollar los procedimientos de registro de imágenes que desembocaron en la edición del primer libro ilustrado con fotografías "El lápiz de la naturaleza", en $1844^{3}$. El propósito de Talbot era continuar y completar con las nuevas técnicas de reproducción de imágenes de su invención la labor taxonómica que había inaugurado el filósofo naturalista sueco Carl von Linne a finales del siglo XVIII, tarea que sería bien acompañada con un sistema de reproducción de imágenes que imitara las muestras botánicas con la máxima verdad y fidelidad, tal como años después continuaría manifestando de manera similar Ramón y Cajal al respecto de las perfección de imágenes que ya era hacía posible, por fin, con los nuevos avances para la fotografía de los colores.

Sin embargo, todo ello no creaba conflicto alguno con la evidencia de que los resultados que se obtenían siempre eran consecuencia directa de los procedimientos y técnicas que se empleaban para ello. Es decir, en aquellos primeros tiempos de desarrollo de las tecnologías de registro y reproducción fotográficas era patente el objetivo común de reproducir fielmente la naturaleza, de aspirar a equiparar la fidelidad de la reproducción a las características del modelo tal como se desprende, entre otros muchos ejemplos, de la carta escrita por el mismo Daguerre en 1828 a Niépce en la que le expresa sus ardientes deseos de ver sus "experimentos tomados de la naturaleza", aunque simultáneamente era del todo evidente y asumido que los resultados de tales experimentos estaban determinados por los métodos y técnicas empleadas. La descripción del proceso del daguerrotipo, publicada por primera vez en septiembre de 1839 por su inventor, es una de las más definitivas a este respecto: "Este procedimiento consiste en la reproducción espontánea de las imágenes de la naturaleza proyectadas mediante la cámara oscura, no con sus propios colores, sino con una extraordinaria delicadeza de gradación de tonos", es decir, ni siquiera era necesario que la reproducción fuera en color, bastaba con que la reproducción fuera espontánea y con el detalle necesario dando como resultado en cualquier caso una reproducción que estaba siempre sujeta a la interpretación, es decir, era independientemente del modelo.

No obstante, aún siendo éste el ánimo de los primeros impulsores de los métodos fotográficos, el entusiasta clima científico que se había impuesto en los siglos de la llustración respecto a la utilidad de los instrumentos de soporte a la investigación científica. Entonces la Ciencia había sido espoleada por los enormes avances en la explicación de los fenómenos naturales que se habían logrado a partir de los hallazgos de Keppler, Galileo, y Huygens entre otros muchos y que culminaron en las sintéticas ecuaciones de Newton publicadas en 1687 en los Philosophia Naturalis Principia Mathematica, para cuyo estudio fueron imprescindibles los avances tecnológicos y mejoras en la instrumentación óptica. Con la ampliación de los horizontes de la visión más allá de lo conocido hasta entonces pronto los instrumentos científicos, una vez adoptada la fotografía con plenos derechos como uno más de ellos en el seno de la Ciencia, se 
situaron a la vanguardia del avance del Conocimiento, haciéndose imprescindibles y, lo que es más preocupante, iniciando un todavía hoy implacable e intenso proceso de borrado de todo intento de explicitar que sus resultados siempre están sujetos a la interpretación, acabando de implantar así un modelo epistemológico caracterizado por la tiranía de una supuesta objetividad que proporcionaban las imágenes ópticas posibles gracias a los nuevos instrumentos tecnológicos y, por extensión, también las registradas con los sistemas de reproducción fotográficos.

\section{Ilustración y Fotografía: El tránsito a la objetividad mecánica en Ciencia.}

La euforia lógica que había provocado tales logros científicos resultado de la llustración, y que había dado como resultado inmediato el destierro definitivo del escolasticismo para situar la mecánica en el eje explicativo de todos los procesos naturales, rápidamente se extendió a todo el conjunto de la Ciencia y se empezaron a aplicar los métodos descriptivos empleados para el estudio de los movimientos celestes al resto de ámbitos de la investigación de los fenómenos de la Naturaleza. De este modo al igual que los telescopios habían servido para estudiar los astros se empezaron a utilizar microscopios que permitiesen acceder a un mundo de dimensiones a escalas ínfimas e inaccesibles para nuestra visión.

Galileo construyó su primer telescopio en 1609, y al año siguiente un microscopio, a partir del diseño previo que describía un prototipo holandés de Zacarias Janssen, del que se tiene pruebas de su existencia desde agosto de 1595. No obstante, la idea de superar las limitaciones visuales con instrumentos que asistieran a los sentidos venía de atrás y ya desde la fundación en 1560 por Giambattista della Porta de la Accademia Secretorum Naturae of Napoles, que tuvo su correspondencia en Roma hacia 1602 con la constitución de la Accademia dei Lincei, de la que formaba parte y ejercía Galileo pese a los sucesivos problemas que desembocaron en su enjuiciamiento hacia 1633, se impulsó de manera consciente el perfeccionamiento de la instrumentación científica para hacer visibles los territorios de la Naturaleza que permanecían inexplorados. En 1610 el propio Galileo realizaba observaciones microscópicas de insectos, concretamente de una abeja, y publicaría por entonces una cuidada edición de dibujos detallados de la Luna y las fases de Venus, Siderius nuncius (el mensajero de las estrellas), en la que resumía sus observaciones astronómicas. Algunos años después, la utilización de microscopios de fabricación propia permitió al holandés Antonie von Leeuwenhoek superar algunas de los defectos principales de las ópticas hasta entonces existentes, tales como las aberraciones esféricas y cromáticas, permitiéndole la observación y descripción precisa de microorganismos tales como las bacterias y los espermatozoides, que complementarían la ya de por sí extensa obra ilustrada compendiada por Robert Hooke en su Micrographia, publicada en 1665 y de manera simultánea a la demostración de las teorías sobre la circulación sanguínea de William Harvey que había sido posible gracias a la observación con el microscopio.

En Medicina, al igual que en Biología, aunque el salto cualitativo había sido impresionante no quedaban muy lejos los años en que el anatomista Andreas Cornelius, más conocido como Vesalius, inauguraba el estudio científico del interior del cuerpo y documentaba su funcionamiento con precisos dibujos a escala macroscópica, publicados en De humanis corpori fabrica, en 1543, y que reproducían directamente los órganos internos una vez diseccionados los cuerpos para proceder a su estudio, práctica que se convirtió en habitual en lo sucesivo en los llamados teatros anatómicos en los que se realizaban disecciones públicas con objeto divulgativo y científico, utilizando para ello los métodos de reproducción ilustrados. De igual modo, en fechas recientes se había hecho común la representación mediante ilustraciones de órganos y procesos funcionales, 
especialmente en embriología, utilizando muchas veces para ello modelos tridimensionales realizados con los más diversos materiales, desde el cristal hasta la cera, y otras utilizando gráficos e ilustraciones para comunicar propiedades características.

Durante los siguientes decenios se desarrollaría enormemente la instrumentación científica para hacer posible la investigación de fenómenos hasta entonces no visibles, facilitando importantes avances en multitud de ámbitos científicos, desde la biología a la medicina, e incluso en geología, pasando por la botánica y por supuesto la astronomía, de manera simultánea al cada vez más evidente tránsito del discurso textual hacia la ilustración científica como herramienta explicativa fundamental para presentar los resultados experimentales obtenidos, toda vez que los sistemas tecnológicos de reproducción permitían una difusión ya masiva. Por esas fechas, además, se empezaron a editar las primeras revistas de divulgación científica, con la publicación del Journal des Savants en 1664, y muy poco después diversas publicaciones especializadas que emanaban de las cada vez más numerosas sociedades científicas que se iban constituyendo en torno a las más variadas áreas del saber, entre ellas la Royal Society de Londres, de la que formaba parte Hooke y el propio Newton.

La ilustración científica, en definitiva, se tornó una herramienta habitual para el registro de los resultados experimentales y la descripción de los fenómenos objeto de análisis, hasta el punto de que no era raro que los propios investigadores desarrollaran sobremanera sus talentos artísticos para poder reflejar en sus dibujos la síntesis de sus trabajos, en algunas ocasiones en exceso, tal como se ha criticado al mencionado Hooke en relación a su obra Micrographia, en la que sin pudor alguno dibujó, y mitificó, algunos insectos, entre ellos sobre todo arácnidos, a una escala a la que era imposible verlos con los microscopios de la época.

Por ello, cuando el director del Observatorio de París, François Jean Dominique Arago, presentó públicamente el invento de Daguerre, el día 19 de Agosto de 1839, ante los miembros de la Académie des Sciencies y de la École des Beaux Arts, justificaba con vehemencia su interés por cuatro razones: la originalidad del invento, su relación con las artes plásticas, y su evidentes usos prácticos y, sobre todo, su enorme utilidad para la ciencia. Las técnicas fotográficas enseguida se incorporaron al trabajo científico y aunque hubo unos breves años en que convivieron las ilustraciones científicas junto con las reproducciones fotográficas muy pronto aquellas se consideraron poco más que una extravagancia y fueron rápidamente sustituidas por los procedimientos mecánicos inherentes a la nueva tecnología que tan bien encajaban con las aspiraciones de objetividad para cierto positivismo que, ahora, se vio de nuevo revitalizado. Incluso el hecho de que al principio no captara el color y se añadiese éste a mano no invalidad la autoridad que le otorgaba su enorme capacidad de registrar el detalle. Cuando poco después se comenzaron a publicar fotografías en medios impresos se dio el paso definitivo para dotar a las imágenes de valor documental y, con ello, consolidar definitivamente sus características explicativas e, incluso, probatorias.

Las primeras fotografías astronómicas las realizó el propio Daguerre por encargo de Arago, aunque sin demasiado éxito, lo cual no fue obstáculo para que el ilustre geógrafo y naturalista Alexander von Humboltd acogiera entusiasmado la imperfecta y escasamente nítida imagen registrada en el daguerrotipo que pudo contemplar en enero de ese mismo año, y que le permitiría comenzar a publicar unos años después, en 1845, su obra Cosmos, en la que incluía imágenes fotográficas. Después de la presentación pública de la técnica pronto se sumaron científicos de diversas especialidades, entre los primeros Ettinghausen, quien asistió a la conferencia de Arago $y$, al volver a su laboratorio realizó la primera fotografía de una célula en el microscopio entendiendo tempranamente que la fotografía podía incluso sustituir al especimen para la 
investigación. Pronto se sumaron a los científicos-fotógrafos investigadores como Roger Fenton, quien en 1850 publicó Human Primate Skeleton; Anna Atkins, quien comenzó a realizar taxonomías botánicas registrando sobre papel fotográfico sus colecciones de algas y helechos a partir de 1843; o, unos años después, el Dr. Jules Luys, quien se vió obligado a recurrir a la fotografía para salvar su reputación ante las críticas recibidas por una publicación ilustrada sobre el sistema nervioso central del ser humano, que hubo de reeditar, en 1873 con el título de Iconographie Photographique des Centres Nerveaux, incluyendo setenta impecables imágenes fotográficas y sesenta y cinco litografías que eliminaran cualquier subjetividad en la presentación de sus resultados de investigación (Thomas, 2008). En definitiva, la fotografía, y el subsiguiente énfasis en su supuesta objetividad contingente tal como han argumentado, entre otros, Daston y Galiston recientemente en lo que han identificado como el inicio de un período en el ámbito de la investigación científica al que denominan de "objetividad mecánica" (Daston y Galiston, 2007), se hizo imprescindible, por no decir inevitable, en todas las áreas de investigación científica, incluso el mismo Darwin incluyó fotografías y grabados en Expression of the Emotions in Man and Animals, publicado en 1872, y en algunos casos fueron fundamentales para desarrollos tecnológicos posteriores, como por ejemplo las cronofotografías realizadas por el fisiólogo Jules Marey, antecendente inmediato del cinematógrafo, o las publicadas en 1884 por Ottomar Anschütz que representaban una secuencia de cigüeñas despegando, volando y aterrizando, y fueron determinantes para el nacimiento de la aviación moderna ${ }^{4}$. E igualmente ocurría en otros ámbitos, como la medicina, en ocasiones sin tanta utilidad y sustentando peregrinas teorías y experimentos, como los que puso en práctica Ducheme de Boulogne, quien publicó en 1862 Mécanismes de la Physionomie Humaine recogiendo fotografías con las reacciones de enfermos mentales, a quienes aplicaba electrodos para visualizar en el rostro la contracción producida por cada músculo, aunque hubieron también otras publicaciones como La photographie medicale, del fotógrafo del hospital de París Albert Londe, que marcaron un hito en la aplicación de la fotografía a la ciencia y contribuyeron sobremanera al desarrollo posterior de la investigación, en este caso en el ámbito médico.

\section{Instrumentación electrónica: Más lejos, más cerca, más color.}

No obstante, todavía habían de producirse algunos descubrimientos trascendentales para disponer de una visión de la Naturaleza mucho más allá de los estrechos límites de la riente visión humana de que hablaba Cajal.

El primero de ellos vino de la mano de Wilhem Röentgen, quien descubrió de forma casual los rayos $\mathrm{X}$ el 8 de noviembre de 1895, cuando estaba experimentando con la emisión de fluorescencia producida por un tubo de rayos catódicos y observó, tras colocar el tubo envuelto en una caja de cartulina negra y oscurecer la habitación, que una hoja de papel recubierto de un compuesto de bario resplandecía aun estando lejos de la caja al conectar el tubo a la corriente eléctrica, denominando a esta energía invisible rayos $\mathrm{X}$. Para presentar su descubrimiento hizo tres fotografías, una de una caja cerrada de madera que contenía objetos, otra de un rifle en el que descubrió una pequeña imperfección, y una tercera de la mano de su mujer, definiendo así los futuros usos de los rayos $X$ en aplicaciones de seguridad, para la detección de fenómenos invisibles a primera vista, y para la exploración médica. Poco después, a principios de la década de 1910, el padre e hijo William Henry y William Lawrence Bragg usaron los rayos X para realizar medidas precisas de distancias entre las filas y columnas definidas de algunos átomos de cristal, comprobando que había distintos patrones de difracción en función de los materiales que exploraban, lo cual les llevó al desarrollo de la cristalografía de difracción de rayos X, técnica de 
exploración de la que se valdrían más tarde, en 1952, Rosalind Franklin y Raimond Gosling para fotografiar la estructura de doble hélice de las cadenas de ADN, imágenes que serían fundamentales para que un año después James Watson y Francis Crick pudieran explicar su estructura molecular, lo que les hico acreedores del premio Nobel de medicina, recibido en 1962.

El segundo gran descubrimiento científico con que se inauguraba el siglo XX fue el hallazgo de la radioactividad del uranio, en 1896, por Henri Becquerel, quien al seguir las investigaciones de Roentgen experimentando con uranio pensaba que podría registrar la radiación $\mathrm{X}$ emitida por este elemento, pero de manera sorpresiva observó que la energía que registraba una placa fotográfica envuelta en papel negro era mucho mayor de lo esperado y, además, el uranio emitía energía por sí mismo. Pocos años después, en 1902, Marie y Pierre Curie como resultado de trabajar durante varios años combinando y reduciendo fracciones de plechbenda consiguieron aislar un gramo de un nuevo elemento que no había visto nadie y emitía una radiación muchísimo más fuerte que el uranio, tanto que el nuevo elemento, al que llamaron polonio, resplandecía por sí mismo en la oscuridad. En 1903 Marie Curie escribió su tesis doctoral describiendo el fenómeno y por ello, por el descubrimiento y descripción de la radioactividad que además de utilizarse para hacer bombas atómicas ha encontrado aplicaciones de enorme utilidad, sobre todo en medicina, no recibió uno, sino dos premios Nobel: en 1903 junto a su marido y Becquerel, y en 1911 el de química por el hallazgo de dos nuevos elementos, el polonio y el radio. Unos 25 años después del descubrimiento de los rayos $\mathrm{X}$, y con el objetivo de encontrar aplicaciones prácticas que permitieran la localización de submarinos se empezaron a utilizar ultrasonidos, y poco después serían también empleados para el diagnóstico en medicina, comenzando con todo ello a desarrollar sobremanera el estudio del interior del cuerpo humano con métodos no quirúrgicos.

De este modo, cuando Ramón y Cajal empezaba a celebrar la riqueza cromática de las imágenes que podían obtenerse por métodos fotográficos, sin cuyo conocimiento habría sido incapaz de mejorar el método de tinción ideado por Golgi, con quien compartiría el Nobel, y poner en práctica sus aplicaciones a la investigación histológica y a las ciencias en general, ya se estaba trascendiendo a grandes pasos el territorio que la instrumentación óptica y las tecnologías de registro fotoquímico habían conquistado con tan merecidos esfuerzos, y se estaba, simultáneamente, empezando a producir de manera irreversible un profundo cisma que ponía en crisis definitiva la inmediata contigüidad entre los datos observados y los resultados científicos obtenidos pues ya era evidente que la investigación científica era sólo posible a través de instrumentos.

Los primeros microscopios se construían con una lente simple de vidrios que adolecían de importantes aberraciones ópticas, escasa capacidad de aumento y una gran pérdida de nitidez y luminosidad pero, a medida que fueron desarrollándose mejoras en los sistemas de fabricación y los materiales y sistemas de montaje de las lentes, se fueron superando progresivamente esos inconvenientes hasta alcanzar, en las primeras décadas del siglo $\mathrm{XX}$, aumentos superiores a 1000X, cerca del límite teórico de resolución que pueden proporcionar los microscopios ópticos, el límite de la longitud de onda del espectro visible. Para entonces se había conquistado también la parte no visible del espectro electromagnético, tanto en la banda del IR y el UV como los rayos X y gamma, que permitían desvelar territorios inexplorados hasta no hacía mucho tiempo y penetrar en estructuras subatómicas mediante técnicas de análisis de difracción o, por ejemplo, analizar radiaciones provenientes de lugares del Cosmos inaccesibles hasta entonces.

Sin embargo, los límites de los instrumentos ópticos no permitían un aumento mayor de 10 micrones, $10^{-6}$ metros, una magnitud algo mayor que el diámetro de, por ejemplo, un cabello humano, de unos 75 micrones, y por lo tanto una capacidad de resolución muy inferior a la necesaria para estudiar estructuras atómicas, pues las dimensiones del mayor de los elementos 
conocidos, el hidrógeno, son de un diámetro de unos $10^{-10}$ metros aproximadamente. Estas fronteras infranqueables con los microscopios ópticos hicieron imprescindible el desarrollo de instrumentos de visión que pudieran superar estos límites de resolución, haciendo posible traspasar esas fronteras hacia 1931, año en que Ernst Ruska ideó el primer prototipo de microscopio electrónico de transmisión (MET), invento que le hizo merecedor de un Nobel en 1986 por su trabajo de investigación al respecto. Con el MET, se inaugura, al tiempo que una nueva era para el estudio de las dimensiones microscópicas hasta entonces inaccesibles, un nuevo procedimiento investigador estrechamente dependiente del instrumental utilizado para el análisis científico y que proporcionaba ya información que estaba alejándose a pasos agigantados de la directamente discernible con los instrumentos clásicos, tales como los microscopios ópticos, que todavía eran extensiones de la percepción con ciertas analogías con los sentidos con que se nos muestra la Naturaleza, e inaugurando plenamente la era de la investigación científica mediante artefactos, con la consecuente e irremediable generación sistemática de nuevos artificios, sin que estas nuevas técnicas de escrutinio de la realidad estén necesariamente teñidas con notas peyorativas respecto a las prácticas científicas de épocas anteriores.

EI MET está basado en la incidencia de un haz electrónico que, guiado por un sistema de imanes y a través de un conjunto de lentes, atraviesa una muestra muy fina que se toma como objeto de estudio para registrar su imagen en la parte posterior de esta en un soporte de grabación, hoy día mediante sensores fotoeléctricos y en soportes digitales.

La comercialización de estos instrumentos electrónicos de análisis microscópico comenzó en 1839, de manera simultánea a que comenzara la experimentación, a partir de 1935 con sistemas que aprovechasen los electrones secundarios reflejados por la superficie de la muestra, llevada a cabo por Max Knoll, antiguo colaborador de Ruska en la invención del MET que trabajaba en el departamento de televisiones de Telefunken. Sus trabajos darían lugar hacia 1839 al desarrollo del microscopio de transmisión-barrido de Von Ardenne, que sincronizaba el barrido del haz con el movimiento de una película fotográfica para el registro de la imagen explorada, consiguiendo así unas imágenes cuya resolución depende del diámetro del haz de electrones y su función de transferencia al sistema de registro empleado. El MEB se vio enseguida complementado por otro instrumento de análisis, la microsonda de exploración electrónica (MSE), de concepción y funcionamiento muy semejante pero destinada al análisis químico de materiales, actualmente de amplia implementación en diversas áreas de investigación y fundamental para el trabajo científico.

Sin embargo, a pesar de sus muchas ventajas, en los microscopios electrónicos hay algunos inconvenientes, entre los más importantes está que es difícil alcanzar la precisión necesaria para analizar exclusivamente la parte específica de electrones incidentes útiles para reflejar las características de la muestra explorada y, también, resulta inconveniente la necesidad de metalizar las muestras a analizar para poder obtener una intensidad de señal suficiente para el análisis, lo cual no permite trabajar con tejidos u organismos vivos, aunque esta es una limitación que ya está dejando de ser tal con la progresiva implantación de los nuevos microscopios de barrido ambiental en la investigación biológica. ${ }^{5}$

Similares técnicas de exploración mediante instrumentación electrónica se comenzaron a utilizar en astronomía, analizado cada vez más unos datos cuya naturaleza resulta del todo ajena a la que el sentido humano de la vista permite percibir de manera inmediata tanto espacial como temporalmente.

Las primeras fotografías de la Tierra desde el espacio se obtuvieron en 1961 cuando el cosmonauta ruso German Titov, que estuvo durante 25 horas circunnavegando el planeta pudo 
registrar en soporte fotoquímico las primeras imágenes exógenas del planeta, unas imágenes de calidad y colores tan impactantes que desataron gran entusiasmo y determinaron sobremanera el ulterior impulso al desarrollo de la investigación y de los instrumentos y sensores que facilitarían el posterior desarrollo de sistemas de teledetección, de tanta importancia para el análisis de los fenómenos atmosféricos, de las plagas vegetales, la prevención de incendios, para prospección minera y geológica, o los estudios sobre desertificación, entre otras muchas aplicaciones. Estas primeras fotografías desde el espacio registraban la luz visible sobre soporte fotoquímico, algo que sería a partir de entonces poco habitual, pues pronto se impondría la exploración electrónica y los telescopios actuales, refractores o reflectores, ni siquiera disponen de ocular, sino de detectores diversos específicos para diferentes longitudes de onda, pero eran una muestra más del enorme impacto e influencia que iba a tener la obtención de imágenes espectaculares y la importancia que éstas tenían para determinar el desarrollo ulterior de la investigación científica en una u otra dirección.

\section{Los límites de la exploración: Imágenes científicas y Artefactos tecnológicos.}

La exploración astronómica actual esta basada en instrumentos que recogen la luz que concentra el sistema óptico en el plano focal para su análisis espectroscópico, un método de investigación descrito por Gustav Kirchoff y Robert Bunsen en las últimas décadas del siglo XIX a partir la demostración de la relación existente entre las líneas del espectro y la composición química del objeto radiante, fundamento inaugural de la astrofísica. El sueco Angström demostraría por entonces la presencia de hidrógeno en la atmósfera solar utilizando la técnica espectrográfica, que iría perfeccionándose durante las siguientes décadas hasta la actulidad, y hacia 1912 la americana Henrietta Leavitt ideó un método para estimar la distancia de las estrellas a partir de la observación de algunas enanas rojas ${ }^{6}$, que hoy se estudian teniendo en cuenta el efecto Doppler y se analiza su situación a partir de las demostraciones matemáticas que hizo Edwin Hubble, quien había estudiado con detalle el registro fotográfico del cosmos y concluyó la existencia de infinidad de galaxias en movimiento, hacia 1929, evidencia que probaba la expansión del universo a una velocidad proporcional a la distancia a la que se encuentran en cada momento. De este modo, Hubble establecía, como en otros casos comentados, una conclusión científica de carácter matemático a partir de la observación de imágenes que habían sido obtenidas mediante instrumentación óptica, en este caso registradas en soportes fotoquímicos.

En astronomía se ha ido mucho más allá, valga la redundancia, pues el problema fundamental que se tenía para entonces era la imposibilidad de estudiar las radiaciones electromagnéticas que eran absorbidas por la atmósfera, ya que ésta sólo deja pasar algunas bandas de microondas y las ondas de radio entre $10 \mathrm{~mm}$ y $10 \mathrm{~m}$ de longitud, limitación que hacía necesario sacar los instrumentos de observación fuera de la atmósfera para poder continuar explorando los confines del universo a partir de energía detectable con la instrumentación científica. Este hito se alcanzó con la puesta en órbita, en 1989 , de telescopio Hubble ${ }^{7}$ con el que se han detectado varios millones de galaxias hasta hace poco desconocidas a partir del estudio de los miles de imágenes que se han considerado útiles para la investigación astronómica, a pesar de que al poco tiempo de su lanzamiento se detectó un error mecánico en los espejos que comprometía la calidad de los datos obtenidos.

De este modo, también los límites de la visión astronómica se han extendido hasta prácticamente los confines del conjunto de radiaciones electromagnéticas, hoy en día detectables con sensores específicos integrados en complejos sistemas de análisis de datos que proporcionan, por ejemplo, 
las hermosas y coloridas imágenes de nebulosas lejanas o las más cotidianas imágenes de los informativos de televisión en las que se representan gráficamente los fenómenos atmosféricos que determinan la previsión meteorológica diaria pero que, a diferencias de las imágenes captadas por Titov, no son sino el resultado del análisis de ingentes cantidades de datos recibidas desde los satélites que una vez tratados se presentan gráficamente y en forma de imágenes de síntesis.

En medicina y otras áreas de conocimiento, de similar manera, se ha ido desarrollando sistemas tecnológicos de instrumentación científica cada vez más complejos con el objetivo de ampliar los horizontes de la visión no sólo a magnitudes macroscópicas y microscópicas, si no para, tal como anticipó Roëntgen en sus experimentos en los que obtuvo las primeras radiografías de rayos X, penetrar en dimensiones ocultas a la visión humana directa, tanto con objetivos médicos como para desvelar secretos ocultos, como ocurre con los escaners simples de cualquier aeropuerto, evolución tecnológica de los primeros sistemas de rayos $\mathrm{X}$, aunque adaptada a los sistemas electrónicos actuales por medio de sensores específicos y sistemas de representación visual de los datos adecuados.

En la exploración médica, desde la comercialización de instrumentos de obrención de imágenes para el diagnóstico como la Tomografía Computerizada (TC), la representación de la enfermedad y el análisis patológico inició una irreversible senda de investigación con instrumentación científica destinada a la invasión óptica del interior cuerpo humano para su estudio con tecnologías digitales de generación de imágenes de síntesis, que comenzó con el desarrollo de estas técnicas TC a partir de 1967, por lo que otorgaron un Premio Nobel en 1979 a su inventor, Godfrey Hounsfield, compartido con el sudafricano Allan Cormack que había desarrollado un instrumento similar. Esta técnica tomográfica, hoy conocida en su actual implementación para el análisis médico como TAC (Tomografía Axial Computerizada), está basada en la exploración mediante rayos $\mathrm{X}$ de la parte del cuerpo a estudiar alrededor de su eje axial, lo cual permite la posterior generación de una imagen completa de esa sección para su análisis en forma de rodaja, una imagen que, insistimos, es resultado de los datos obtenidos, no es el registro óptico directo sobre una emulsión o soporte sensible. Para realizar un TAC,además, a veces es necesaria la utilización de compuestos intravenosos que faciliten la obtención de los datos aumentando el contraste entre las estructuras a analizar y las contiguas, resaltando así o seleccionando con más precisión el tipo de aspecto susceptible de análisis por considerarse de interés clínico. De manera similar, se realiza la exploración con otras técnicas y métodos de diagnóstico médico como la Tomografía por Emisión de Positrones (PET), basada en el análisis funcional de estructuras internas por las que se hacen circular isótopos radioactivos para detectar posteriormente su tránsito y generar con ello imágenes tridimensionales que representan además el vector temporal, técnica que se combina con el TAC para complementar los resultados obtenidos. Una tercera técnica de diagnóstico, la Resonancia Magnética (RM), o RMf en su versión funcional, utiliza imanes para alterar los campos magnéticos de las estructuras orgánicas que se pretende analizar para, después, al igual que las anteriores, detectar tales variaciones para deducir mediante el análisis de los datos obtenidos las características estructurales pertinentes para el diagnóstico médico.

Lo que resulta evidente a poco que se haga un sencillo análisis de cualquiera de las técnicas e instrumentación que se utilice para la exploración científica de señales de cualquier magnitud y naturaleza con las que se generan imágenes destinadas a la demostración científicas o precursoras para la diagnosis de fenómenos del tipo que sean es que, insistimos, fijemos el objetivo del instrumento electrónico en cualquier magnitud, objeto o área de investigación, la obtención de datos útiles para la generación de imágenes que sean significativas y pertinentes en relación al objetivo del análisis, se enfrenta a aspectos críticos que tienen un claro carácter electivo e intencional y que, sin duda, deben también ser objeto de análisis. Entre los más importantes, en primer lugar, se encuentran los debidos a la complejidad intrínseca que tiene la 
segmentación de los datos resultantes de la exploración y la posterior selección de aquellos que se consideran útiles en función de los objetivos del análisis y, en segundo lugar, a las importantes dificultades asociadas a las interferencias y ruidos instrumentales inherentes a la instrumentación óptica y a los tipos de sensores empleados para la obtención y registro de las señales.

En este punto, entonces, se hace necesario retomar la clásica concepción aristotélica de los artefactos que nos puede permitir, con alguna modificación y matiz, caracterizar la naturaleza de los sistemas tecnológicos de obtención de imágenes que utilizamos para la investigación científica en tanto que objetos, según esta concepción clásica, sin esencia alguna y sólo clasificables en relación a sus características funcionales. Una definición sin duda que necesita precisarse pues se establece a partir de la confrontación de una suerte de esencia intrínseca sólo atribuible a los humanos frente a agregados de materia funcionales como son los objetos en tanto que meras cosas sin más identidad que su carácter formal y funcional, tal como han hecho Kroers y Meijers (2006) remarcando su naturaleza híbrida en tanto estructuras físicas previamente diseñadas y con funciones que se refieren a la intencionalidad humana, estableciendo el concepto de función como puente y mediador entre lo físico y lo intencional. Es decir, entendiendo que los artefactos no sólo son el resultado de la acción humana si no que en su propia concepción previa, en su diseño, se halla incrustado de manera indefectible el concepto de intencionalidad que determina los criterios normativos que permitirán que las funciones a realizar por el artefacto permitan alcanzar los resultados esperados con éxito, es decir, cumplan las predicciones para las que se diseñaron. $O$ tal como ha señalado Houkes $(2006,106)$, un artefacto en su concepción ha de proporcionar "razones para hacer algo, más que razones únicamente para creer algo", es decir, dado un deseo y condiciones de disponibilidad, conocer que el objeto tiene una función posible proporciona una razón prima facie para usarlo. Y aún podríamos ir más allá, tal como ha argumentado recientemente Baird (2004) respecto a cierto tipo de artefactos tecnológicos que no sólo generan conocimiento técnico si no que lo expresan, entre los cuales podríamos incluir los sistemas de instrumentación que se utilizan para la obtención de imágenes con fines científicos. Es decir, el cumplimiento de la función para la que están diseñados permite el dominio del conjunto de fenómenos que expresan y, por tanto, el tipo de conocimiento que crean partiendo de la supuesta "verdad material" para cuya expresión han sido diseñados.

Todo ello es coherente, tal como argumenta Vega Encabo (2009) con "dos actitudes muy diferentes en cuanto al tipo de valores que son encarnados y objetivados a través de los objetos técnicos: para muchos, no hacen sino conformar un espacio valorativo en el que se imponen todos aquellos valores ligados al éxito instrumental, como la eficiencia, y configuran un modo de vida funcional; para otros, los mismos artefactos incorporan valores, en el sentido en que efectivamente ciertas propiedades de valor ético, político o cultural cobran vigencia y fuerza vinculante a través de los mismos objetos".

Es decir, tomando como ejemplo la exploración astronómica o, también, en lo relativo a la eficacia de los sistemas de teledetección, para obtener datos válidos se han de introducir algoritmos de corrección geométrica y sistemas de filtrado en los sistemas de instrumentos que permitan la discriminación de las señales. Así ocurre, por ejemplo, cuando se quiere obtener imágenes que sean útiles para la detección de aerosoles de efecto invernadero, para lo cual se necesita considerar tanto los errores en la radiancia media y reflectividad de la superficie terrestre como la influencia del ozono en la medición, variables que no habían sido consideradas hasta fechas recientes y que obligaron a que la National Oceanic and Atmorpheric Administration (NOAA) cambiara el algoritmo de análisis de los datos proporcionados por sus sensores en los satélites para introducir nuevos parámetros como la reflectividad del mar y hacer los datos más eficaces (Sobrino, 2000). 
Igualmente, en análisis microscópico con instrumentación electrónica o en sistemas de diagnóstico médico, se ha de tener en cuenta las características de las ondas que llegan a los sensores una vez han interaccionado con los diferentes tejidos, órganos o estructuras moleculares, haciéndose necesario el uso de complejos algoritmos que permitan reconstruir la zona original de exploración para, posteriormente, tratar los datos desde un sistema de generación de imágenes de síntesis que, en cualquier caso, se obtienen a partir de valores numéricos digitales con los que se pretende emular fenómenos que son invisibles a nuestra percepción con imágenes adecuadas a nuestra riente visión humana. Es decir, no existe un único camino, si no que las imágenes obtenidas son el resultado de combinaciones o selecciones entre varios candidatos físicos posibles, en muchas ocasiones fruto de procesos subjetivos de discriminación que dotan de significado a determinados datos sobre otros haciéndolos resaltar de un conjunto de ellos que se muestran como continuos, tal como ocurre por ejemplo en exploración médica para distinguir órganos funcionales utilizando colores contrastados que, fisiológicamente, no siempre existen más que como un conjunto continuo de tejidos.

Es decir, ya no se trata, por tanto, de reproducir con fidelidad los colores para superar la visión de búho que proporcionaba la fotografía de principio de siglo, como soñaba Ramón y Cajal, sino que hoy en día el reto está en elaborar representaciones visuales a partir de gran cantidad de datos que se consideren pertinentes y útiles para realizar con ellos ulteriores reelaboraciones que puedan hacerlos comprensibles y óptimos para su estudio, creando para ello un espacio normativo marcado por la necesidad y la posibilidad de que la adecuación de los sistemas técnicos a los objetivos para los que están diseñados hagan efectiva tal intencionalidad bajo las condiciones impuestas de logro y éxito funcional

\section{Conclusiones.}

En definitiva, el impresionante desarrollo en sistemas de detección y registro de fenómenos ha trascendido con creces la visión del búho y la ceguera visual de los órganos perceptivos humanos al limitado espectro visible, y ya nada tienen que ver los fundamentos de los actuales sistemas de obtención de imágenes científicas con los presupuestos en que se sustentaba el estudio y la reproducción de los fenómenos de la Naturaleza, término complejo y de límites imprecisos donde los haya, mediante los sistemas de captación y registro de imágenes de principios del siglo pasado.

Al contrario que ocurría, hoy en día hay una distancia formal cada vez mayor entre la imagen y el objeto que ésta representa y la presencia determinante del artefacto es absoluta, dando como resultado un imparable proceso abstracción progresiva de los fenómenos hasta hace poco años directamente perceptibles dándoles forma de valores digitales que se obtienen con la instrumentación actual. El problema de este cada vez mayor alejamiento y mediación es que se hace cada vez más complicado poner en tela de juicio unos sistemas de registro de imágenes que, aún debiendo estar sujetos a constante crítica e interpretación dada la evidente intencionalidad que les caracteriza en tanto que artefactos funcionales, se nos presentan con la convicción de las verdades materiales que están diseñados a expresar. Y, de este modo, las imágenes resultantes de los artefactos tecnológicos que no deberían ser entendidas más que cómo artificios sujetos a crítica constante, transmutan su esencia y se convierten en pruebas prácticamente irrebatibles y verdades indiscutibles, desdibujando como nunca gracias a su 
capacidad explicativa y su valor probatorio los sistemas y mecanismos de producción subyacentes.

El común de los humanos, que hoy como nunca tiene acceso a un mundo perceptivo infinitamente mayor al de hace sólo unas décadas, está desde luego del todo desvalido ante imágenes que se le presentan como verdades indiscutibles, imponiéndole con autoridad técnica una realidad elaborada a partir de un imaginario inaccesible que está en manos, y cuya deriva depende, de sistemas y estructuras de investigación que realizan su actividad en un contexto de gran complejidad y sujeto a dinámicas que se superponen a la propia comunidad científica, obligada muchas veces a presentar sus teorías y resultados de investigación de forma atractiva y contundente. Además de ello, y en parte como resultado de dichas dinámicas productivas, las imágenes científicas se están haciendo inmunes a crítica, incluso para los propios especialistas, para quienes en muchos casos las imágenes con que trabajan son previamente elaboradas por complejos sistemas tecnológicos sujetos a normativas de funcionalidad difíciles de determinar, y no sólo muestran teorías existentes si no que si no que anteceden a la elaboración de nuevos modelos teóricos, de modo que el artefacto se imbrica en el sistema de conocimiento científico actual desde su propia génesis de manera ineludible y, lo que es más preocupante, resguardado de cualquier crítica a partir del borrado de su carácter intencional inserto en la complejidad de los sistemas de producción de conocimiento actuales.

Es decir, las imágenes científicas actuales se sitúan en un lugar indeterminado en el que la representación visual de gran cantidad de datos resultantes de fenómenos físicos acaba por elaborar artefactos complejos que, paradójicamente, queriendo representar lo real acaban por ser sólo un reflejo ideal que se adecua a nuestras necesidades de comprensión ante hechos cognitivamente inaprensibles con nuestras limitadas capacidades perceptivas. Para hacer comprensibles los datos, paradójicamente, se utilizan técnicas conceptualmente no muy alejadas de las empleadas durante siglos para ilustrar pictóricamente los hechos científicos o representar los acontecimientos ${ }^{8}$ y que se pretendieron superadas por la objetividad científica sustentada en la obtención de imágenes mecánicas por medios fotográficos. Sin embargo, hoy día, estas imágenes que no son más que meras ilustraciones no sólo se utilizan como apoyo visual, sino que se imponen ejerciendo un papel fundamental para crear objetos epistémicos por sí mismas, como evidencias que no necesitan en modo alguno ser descifradas, como entidades situadas entre la naturaleza y la tecnología en tanto que artefactos construidos con valor epistémico propio, que en el caso de los organismos vivos la filósofa alemana Nicole C. Karafyllis ha denominado biohechos (Karafyllis, 2003).

En definitiva, y como conclusión, ante cualquier imagen de carácter científico debemos recordar la evidencia ya notada por Baudrillard de que la imagen deriva "de manera irreversible hacia el simulacro" (Baudrillard, 1978), y cada vez se presentan con menos referencias externas y, ante ello, no podemos dejar de preguntarnos siempre algunas cuestiones básicas que faciliten su interpretación y análisis de manera adecuada. Cuestiones tales como, por ejemplo, en qué medida la imagen que se nos ofrece corresponde con su forma física, qué tipo de variaciones se pueden haber introducido fruto de proceso y los instrumentos de registro, cuál es el grado de tratamiento que tiene la imagen y con qué algoritmos específicos y técnicas de aumento del contraste para hacer visibles aspectos que se consideren de interés para la investigación en el área particular de la ciencia para el que se ha creado, si lo observado es una estructura permanente o temporal y, sobre todo, cuáles han sido los parámetros de investigación que guiaban la obtención de esa imagen, con qué fines se han obtenido y quiénes son los principales destinatarios, sin olvidar en ningún caso que las imágenes técnicas no apuntan directamente al mundo exterior, sino que son el resultado del programa contenido en los instrumentos y condiciones previas que condicionan la investigación, y que no son más que el resultado de un artefacto, es decir, un artificio. 


\section{Referencias bibliográficas.}

BAIRD, David (2004): Thing Knowledge. A Philosophy of Scientific Instruments. Berkeley y Los Angeles: University of California Press.

BAUDRILLARD, J. (1978): Cultura y simulacro. Barcelona: Kairós, 1993.

DASTON, L.; Galiston, P. (2007): Objectivity. New York: ZoneBooks.

HOUKES, W. (2006): "Knowledge of Artefact Functions", en Studies in History and Philosophy of Science, 37, pp. 102-113.

KARAFYLLIS, N. C. (2003): Biofacts. Essays on Man between Artefact and living Entity. Paderborn: Mentis.

KROES, P. and MEIJERS, A., 2006. "The Dual Nature of Technical Artefacts", en Studies in History and Philosophy of Science, 37, pp. 1-4.

SOBRINO, J. (2000) : Teledetección. Valencia: Universitat de Valencia.

THOMAS, A. (2008): "La fotografía en pos del conocimiento", en El mundo descrito. Madrid: Fundación ICO.

VALDECASAS, A.; CAMACHO, A. (2005): "On the environmental scanning electrón microscopy for taxonomic purposes", en Invertebrate Biology, 124 pp. 66-73, AMS-American Microscopical Society.

VEGA ENCABO, J. (2009): “Estado de la cuestión: Filosofía de la tecnología”, THEORIA. An International Journal for Theory, History and Foundations of Science, Vol 24, N. 3.

\section{Notas.}

\footnotetext{
${ }^{1}$ Grupo de Investigación ITACA. Research Project "Tendencias actuales en la producción y realización de informativos para televisión: entre el espectáculo, el entretenimiento y la información”, dirigido por el Prof. Javier Marzal Felici.

2 Ramón y Cajal, S. (2007): Fotografía de los colores. Bases científicas y reglas prácticas. Zaragoza: Ed. Prames.

${ }^{3}$ El libro comprendía seis volúmenes con un total de 24 talbotipos originales que iban desde paisajes y vistas arquitectónicas a objetos inanimados, copias de grabados y fotogramas de encajes y objetos similares.

${ }^{4}$ Janssen ya había registrado, en 1874 , con un revolver fotográfico el registro paso de Venus ante el Sol, y a partir de 1897 comenzó a utilizarse la imagen cinematográfica en medicina en Rusia y Polonia para el registro de intervenciones quirúrgicas. La primera película de la serie Mundo invisible se exhibió en 1900, a la que seguirían otras como La circulación de la sangre en el pie de la rana de la serie Mundos ocultos. Hacia 1903-04 se realizan documentales como La vida microscópica dentro de un estanque y La metamorfosis de la mariposa, y años después, en la década de los veinte, ya se empiezan a exhibir películas de carácter divulgativo, concretamente la serie de animación titulada Tres minutos, que trataba diversos temas de interés científico, empezando por la astronomía y continuando con la medicina.

${ }^{5}$ Para un detallado análisis de las posibilidades que ofrecen para la investigación biológica los microscopios ESEM (Environmental Scanning Electron Microscope) se puede consultar Valdecasas, A.; Camacho, A. (2005): "On the environmental scanning electrón microscopy for taxonomic purposes", en Invertebrate Biology, 124 pp. 66-73, AMSAmerican Microscopical Society.
} 


\begin{abstract}
${ }^{6}$ Las Cefeidas, entre las que se encuentra nuestra Estrella Polar, que palpitan a intervalos regulares a medida que se extinguen, y como consecuencia de ello emiten energía en la banda espectral de las ondas largas, de ahí su nombre de enanas rojas, y de ahí que su extinción se denomine desplazamiento al rojo.

${ }^{7}$ El primer satélite artificial se había puesto en órbita en 1957, el Sputnik 1, y un poco después, el 2 de noviembre de ese mismo año, se lanzó al espacio a la perra Laika, el primer ser viviente en el espacio, un hito que abonó el camino al lanzamiento de naves tripuladas y culminó la carrera por la captación de imágenes aéreas sacando las cámaras fotográficas al espacio, práctica que comenzó a realizarse desde los inicios de la fotografía utilizando dirigibles y ya hacia 1909 se tiene constancia de las primeras fotos realizadas por Wright desde aviones, lo cual derivaría en la invención de la cámara automática hacia 1915 por sus evidentes aplicaciones militares.

8 Convertidos en "evidentes" e indiscutibles toda vez son puestos en imágenes, tanto hoy como cuando Goya representaba en una serie de 82 grabados datados entre los años 1810 y 1815 los desastres de la Guerra de Independencia española entre los que abundaban las escenas trágicas como la del grabado número 44, titulado de manera significativa "Yo lo vi", dejando así impronta de ello para la Historia.
\end{abstract}

